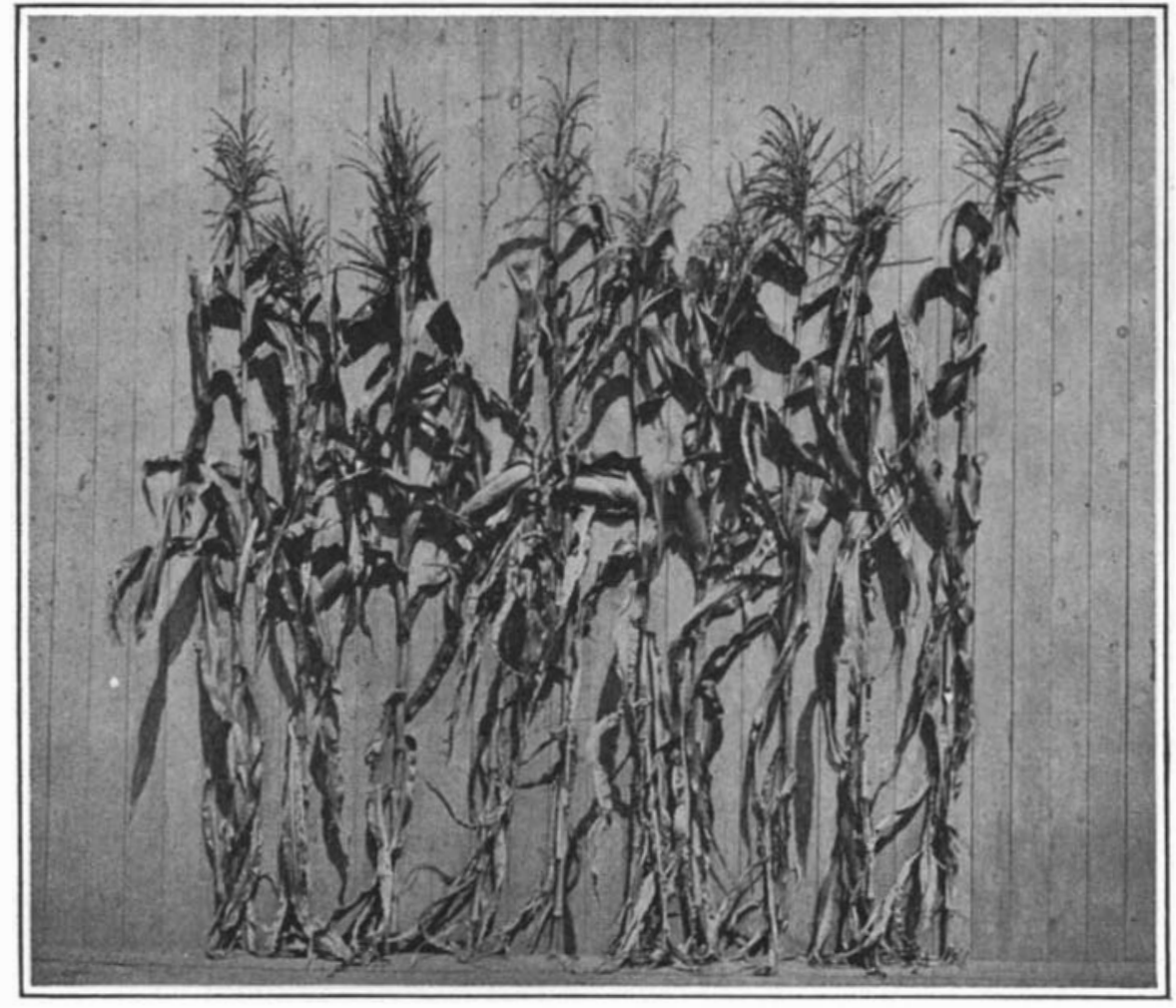
Representative plants of a standard variety before inbreeding
was begun

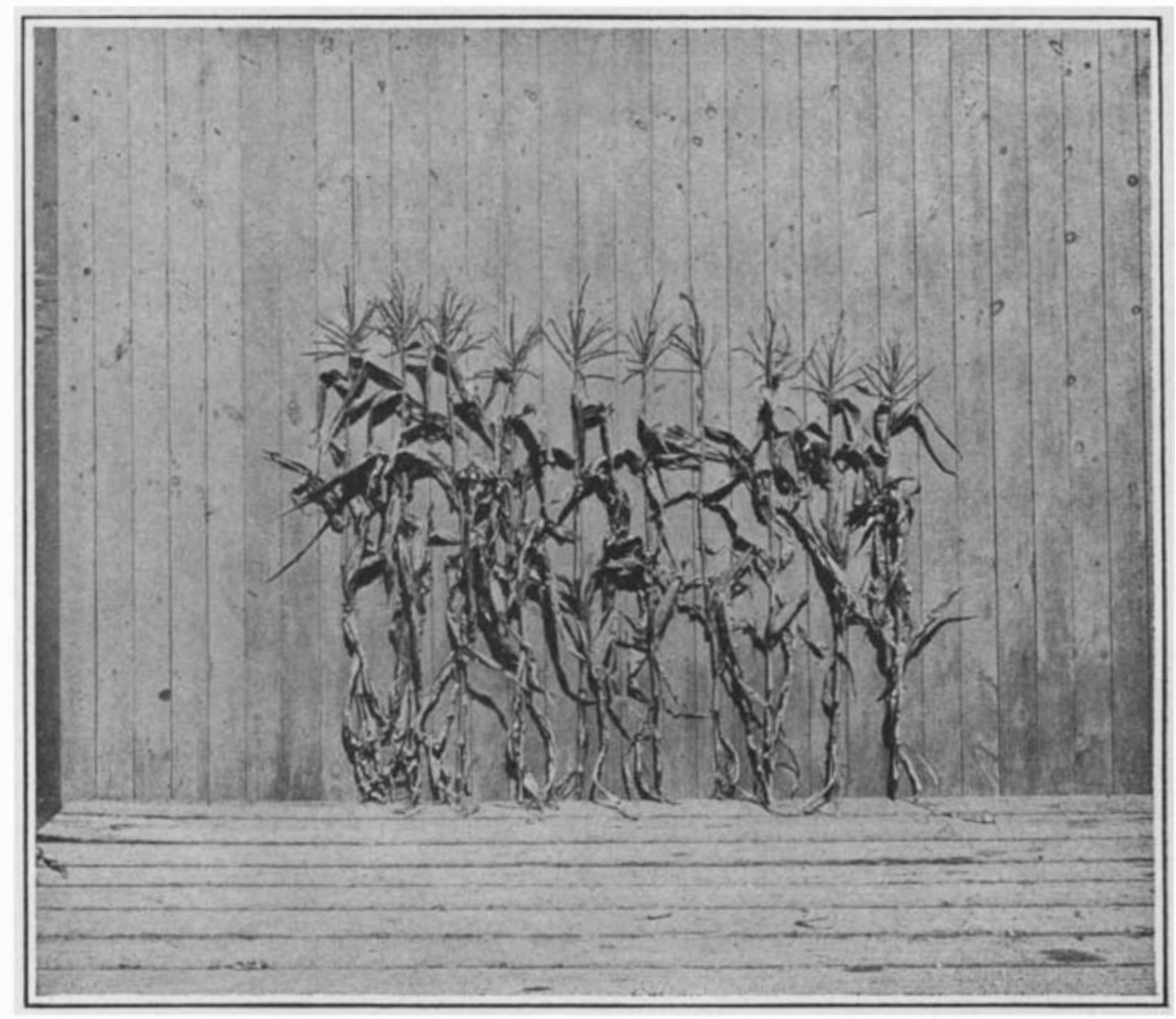

Self-fertilized plants descended from a common normal ancestor.

\title{
Hybrid Vigor and Its Meaning
}

\section{Significant Experiments in Corn at the Connecticut Agricultural Experiment Station}

\section{By D. $i k$. Jones}

ROM the time of Moses it has been known that
crosses between somewhat different animals may crosses between somewhat different animals may
bring about an increase in size and constitutional vigor. The mule, the result of crossing the horse and the ass, is the classical example of this effect. For a long time it has been known to be equally true for the matings of individuals from 'unrelated herds of cattle, swine and sheep. The converse effect of a reduction in size and loss of vigor following close-mating has likewise been recognized. The opinions of the ancient Hebrews in regard to this matter, formulated in their code of laws, the Talmud, have been handed down and em. bodied in our statutes against the marriage of near kin.

The same phenomenon occurs in the plant kingdom although it was not until after the essential similarity of sex in plants as in animals was discovered in the 17 th century that hybrid vigor resulting from the crossing of different plants was put on record. So general is the invigorating effect of crossing that it has been found to occur in all the great plant grouls above the mosses, and in animals in some of the lower organisms as well as the insects, birds and mammals, including nearly all the common domesticated animals and man himself.

The opposite effect when vigorous but related indiriduals are mated has caused many to believe that consanguinity resulting from relationship-marriages, or inbreeding as it is called by live-stock men, is inherently harmful and to be avoided if possible, as it was thought to lead to ultimate extinction. Darwin was one of the chief sponsors of this view and so widespread have become his ideas concerning evolution that it is to be expected that his opinions in regard to the effects of consanguinity should also be generally received. The conclusions of Darwin and his predecessors have been handed on in such phrases as "Nature abhors perpetual self-fertilization," or "It is intended that a sexual intercourse should take place between neighboring plants of the same species," and like many popular slogans they have carried conviction but confused the main issue.

It has remained for recent times to perform extensive and controlled experiments to determine the actual results of close-mating when long continued in order to base reliable conclusions and the interpretation of the results obtained has only been made possible by the recent great advances in the knowledge of the mechanism of heredity.

Plants in many respects are better suited for experiments of this kind than animals because they can be self-fertilized which is the most severe form of inbreeding that can be practiced and results in the greatest consanguinity. The corn plant was chosen because in its natural state it is almost completely cross-fertilized in every generation and would there fore be expected to show change under artificial self pollination. Many exceedingly vigorous plants, both in the lists of cultivated crops and in the wild, are naturally completely self fertilized in every generation and, of course, $c$ and, of course, could not be expected to behave any differently when this process was continued artificially. The corn plant is also admirably suited for experimentation as it has many diverse characters which can be easily observed and measured.

At the Connecticut Agricultural Experiment Station arn has been artificially self-fertilized for thirteen

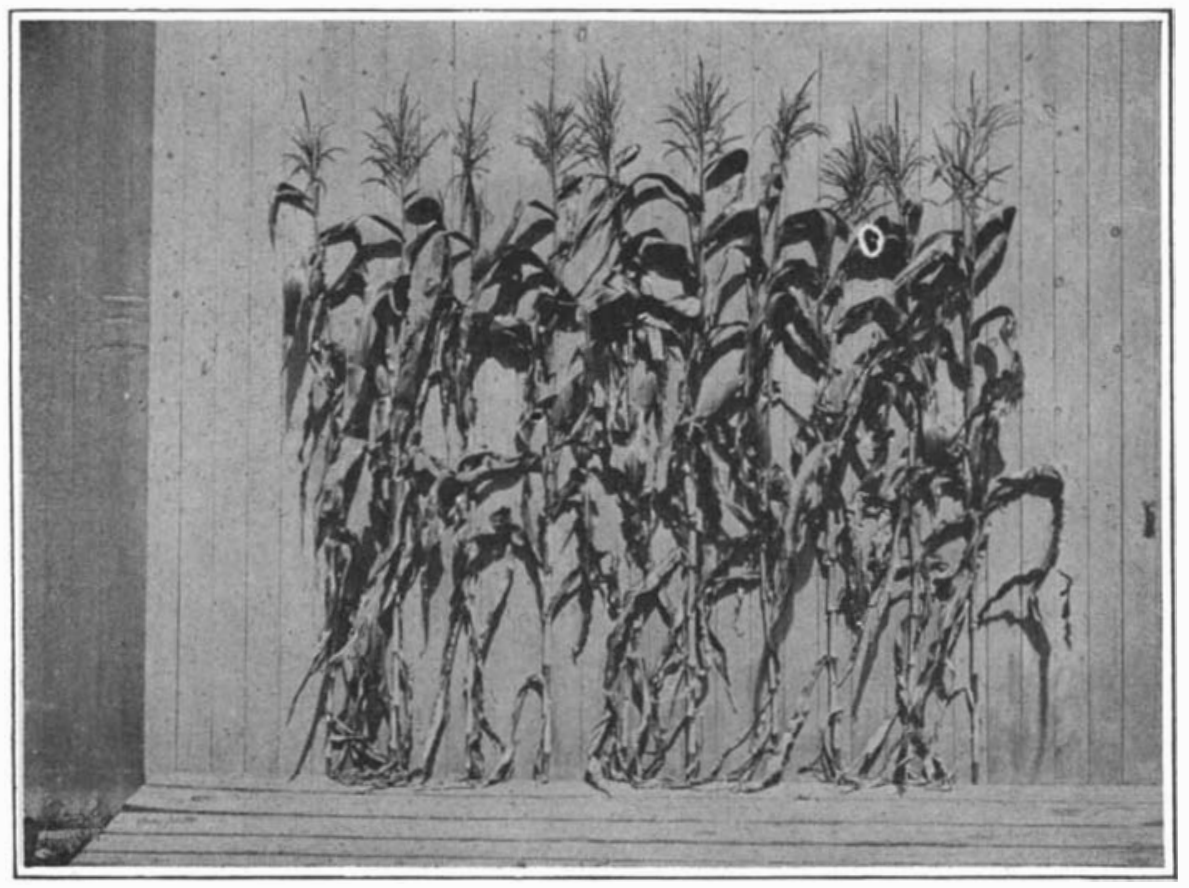

Crossing from inbred parents restores the original vigor, while the inbred uniformity is also retained for the first year

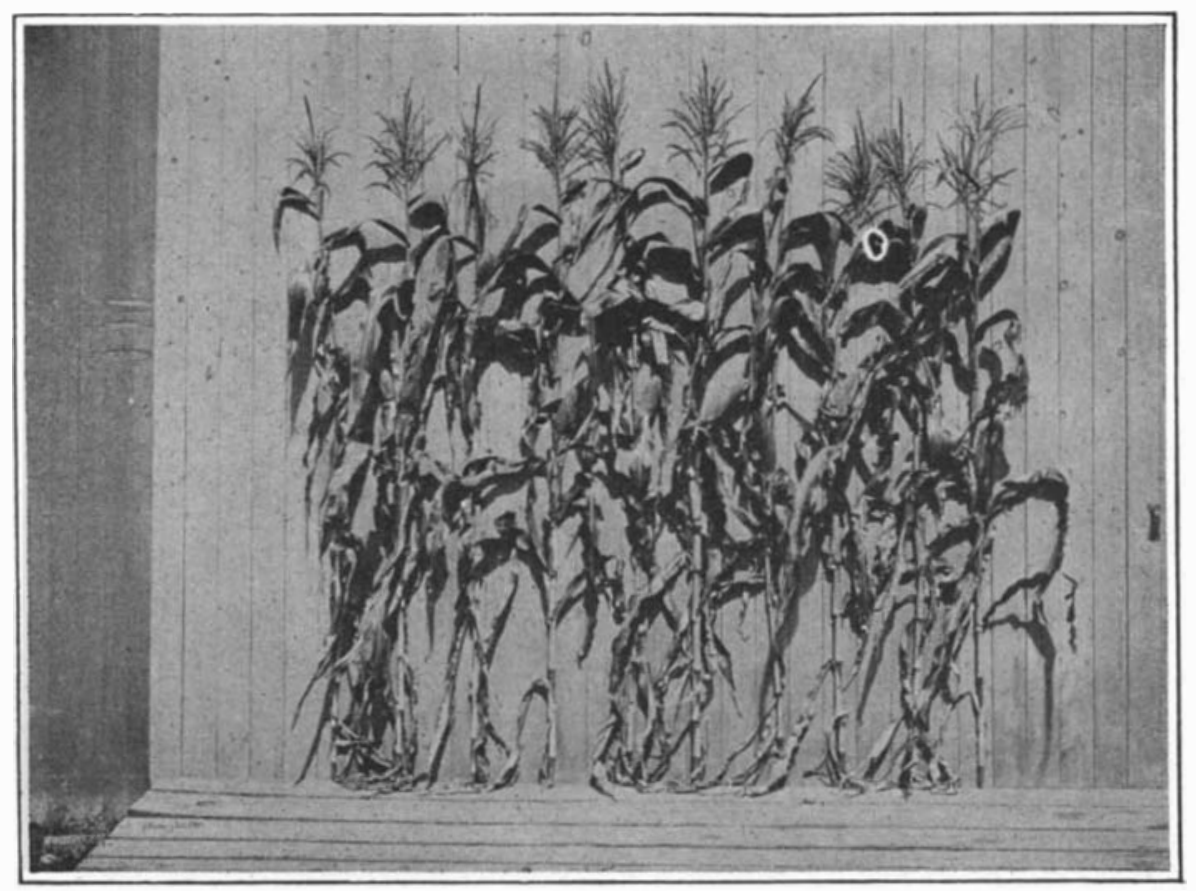

Inbred parents at right, off spring at left, second generation in center. The regained vigor and the inbred uniformity are not permanent 
consecutive y e ars. The outstanding results have been a decided drop in produc tiveness of grain, decrease in size and a lessened ability to withstand unfavorable conditions. All the evil effects com. monly attributed to consanguinity appeared during the course of this experiment. In the first years of inbreeding many very undesirable kinds of plants were observed, -dwiarf plants, sterile plants, albino sedlings which could not grow beyond the stage made possible by the food stored in the seed, plants with
Ears of two inbred lines, showing diversity between strains and uniformity within strains

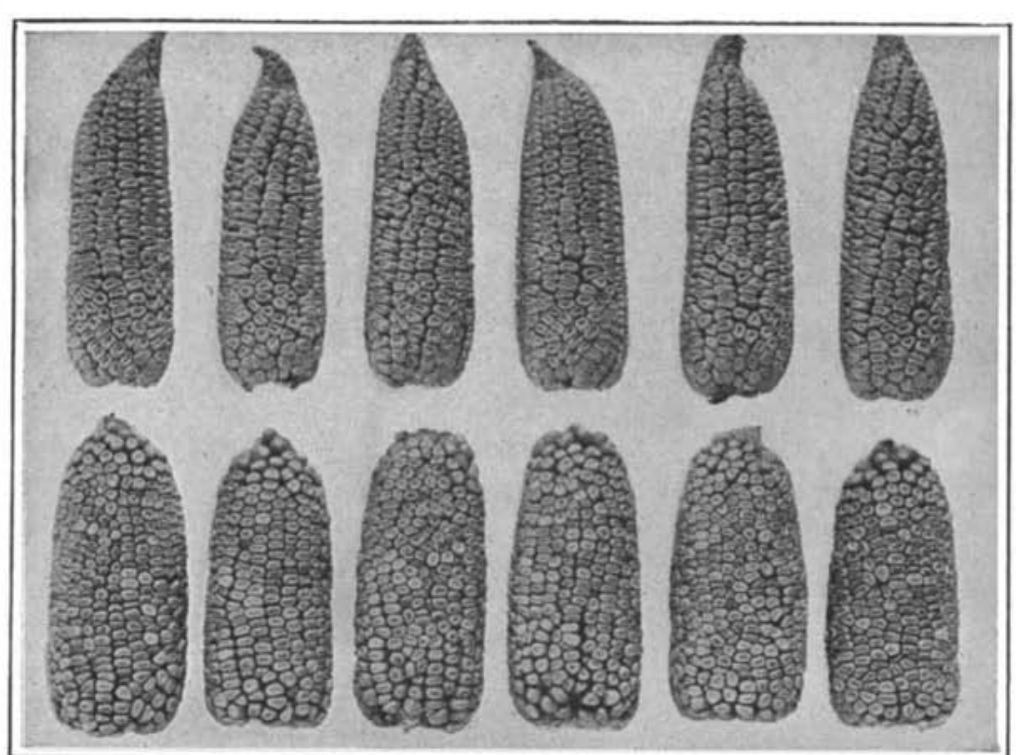

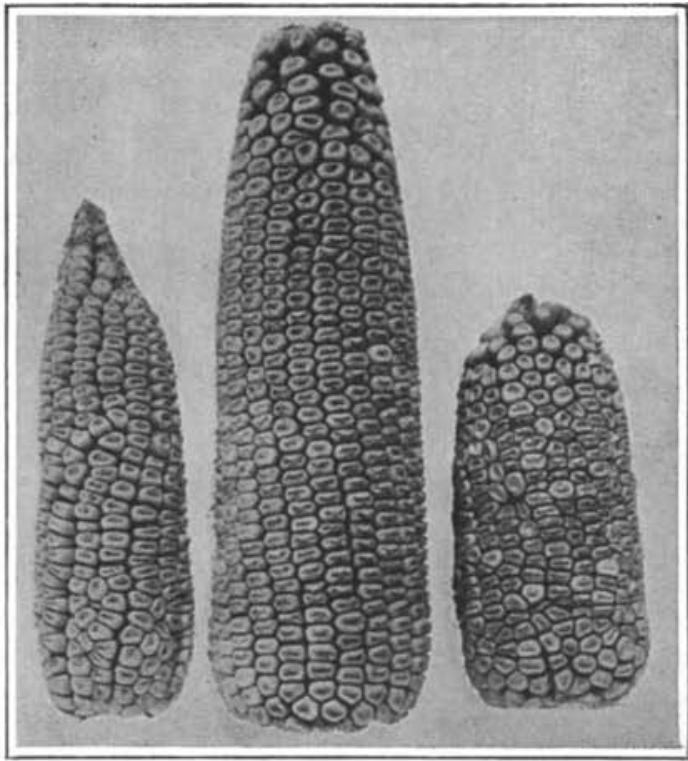

Crossing restores size and vigor. Two inbred
The beautiful conparents is also tained in the first generation following the cross. Not only is size and strength restored by crossing but it may be increased over the condition of the variety with which the start was made due to the uniform excellence of the plants freed from many abnormal and undesirable characters in general. In this way inbreeding has great possibilitics as an actual means of improving naturally cross-fertiized plants and bisexual animals.

For example, in maximum corn pro- leaves instead of the normal dark green foliage. Other plants lacked brace roots and were unable to stand upright, some had reduced tassels and still others had crooked, contorted stems and fasciated ears. Many more peculiarities were found but these may serve as examples. Many of the plants possessing one or more of these unfavorable characters were unable to produce seed. But plants incapable of reproduction ceased their appearance after about six generations of self-fertilization and the remaining inbred plants reached a point beyond which there was no further reduction in size and vigor or alteration in structure. At this stage the self-fertilized plants were from onethird to one-half as productive as the original stock.

During the past five years that these inbred types have been continued there has been no change in details of form, and they have remained on the same low level of vigor. The point to be emphasized, however; is that there is no indication that these continuously inbred plants are on the road to extinction, but on the contrary there is every reason for believing that the can be continued indefinitely by self-fertilization as long as anyone cares to propagate them in that way.

These inbred plants differ in a remarkable manner from the original variety from which they came and from all corn commonly cultivated. This difference is chiefiy in their exceptional uniformity. All the individuals in an inbred line descended from a given normal ancestor are all just alike. In shape of tassel, position of leaves, and characters of the ear one plant is a replica of the other as if all were cut by the same die. There is some variation in size due to inequalities in opportunity to grow, but the similarity in every minor point is readily apparent.

Although within the lines, each descended from different individual plants at the start, there is great similarity, the differences between the several lines themselves are striking. For example, some strains have fiat, uncolored cohs with small seeds. Other differences in the shape of the tassels, stalks and habit of growth characterize the various inbred lines so that they are at once recognized.

so that they are at once recognized. ers. No single feature is common to all inbred plants, so that consanguinity does not produce any particular infavorilhle effect. What is most important is the fact that the injury from inbreeding loes not lieep on accumulating but the inbred plants ultimately reach a stage after which there is no further alteration either up or down.

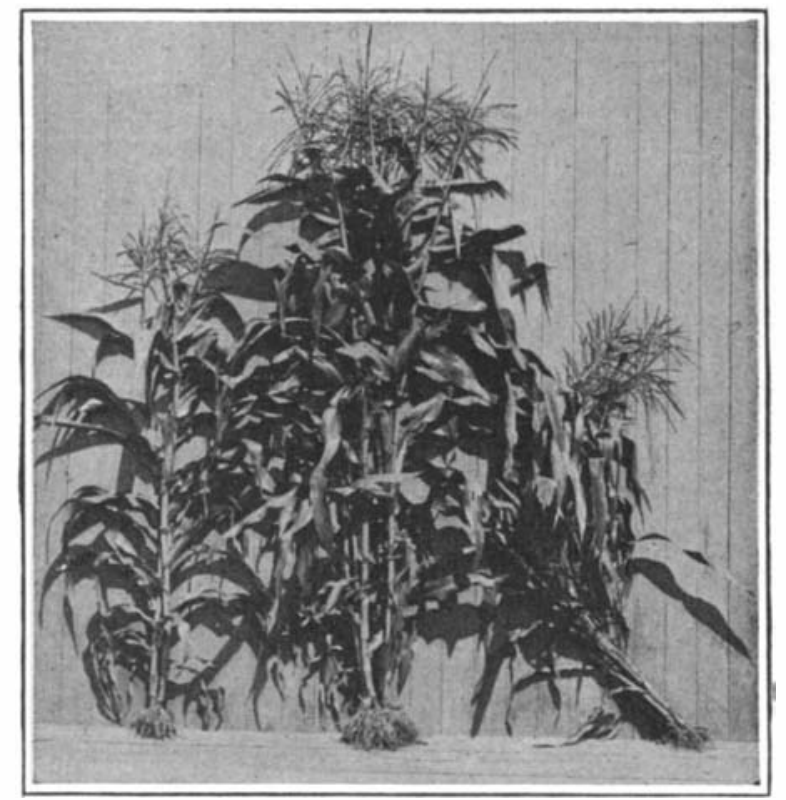

Crossing combines the best from both parents. Inbred plants at right lack brace-roots, those at left do hybrid in the center displays neither of these defects

In the process of inbreeding a large number of decidedly unfavorable characters are eliminated. This is a decided benefit but productiveness and general vigor are also lost. Crossing. in proper combinations, restores immediately what is lacking in this respect.

duction the factors which count heaviest are a perfect strain of plants with each plant producing at least a moderately good ear of corn. If this were true for every field of this most valuable plant in America, an unbelievable increase in production would be made possible. But as it is, a large number of plants in a corn field produce either nothing or only nubbins. The corn which the farmer shovels into the corn crib looks far different from the prize-winning specimens exhibited at the corn shows. The prize takers are the result of an especially favorable inheritance accompanied by the best opportunity to grow. Both must work together.

By inbreeding, if carried on long enough, all the individuals of one ('onsanguineous line are brought to have the same heredity. When two different inbred lines are crossed the first generation grown from the crossed seed are likewise hereditarily all alike, being the combination of uniform parental types. Since actually vigor is regained the uniformity of the first generation hybrid plants is an important factor in their good performance. In such hybrids there are no barren plants or weaklings. Not all individuals are $a b$ solutely alike because external conditions are never always the same. But a field of such plants differs in a very decided way from ordinary corn fields.

The uniformity characteristic of inbred parents and the hybrid does not continue beyond the first generation. Neither is the yielding power of such hybrids capable of fixation by any practicable means now known. If the hybrid individuals are selfbred or bred among themselves a rapid reduction in growth takes place which if persisted in will take the plants back to the level of the inbred parents which were used to make the cross. This has been abundantly demonstrated and therefore hybrid vigor is transitory in its (Continued on page 239)

Uprooting a Tree With Dynamite

WHAT is believed to have been the largest tree in the eastern states was blown up the other day at Spinnerstown, $\mathrm{Pa}-\mathrm{a}$ fate which the photograph taken before the blast indicates to have been long they unlike in respect to productiveness, ability to withstand unfavorable cond it i o n s, time of fiowering and maturing, and resistance to disease. All these results of inbreeding can be summed up briefly in the simpl statement that diverse types are finally produced which remain un changed as long a self-fertilization is continued. Som are unable to survive but many can and of these some are clearly better than oth

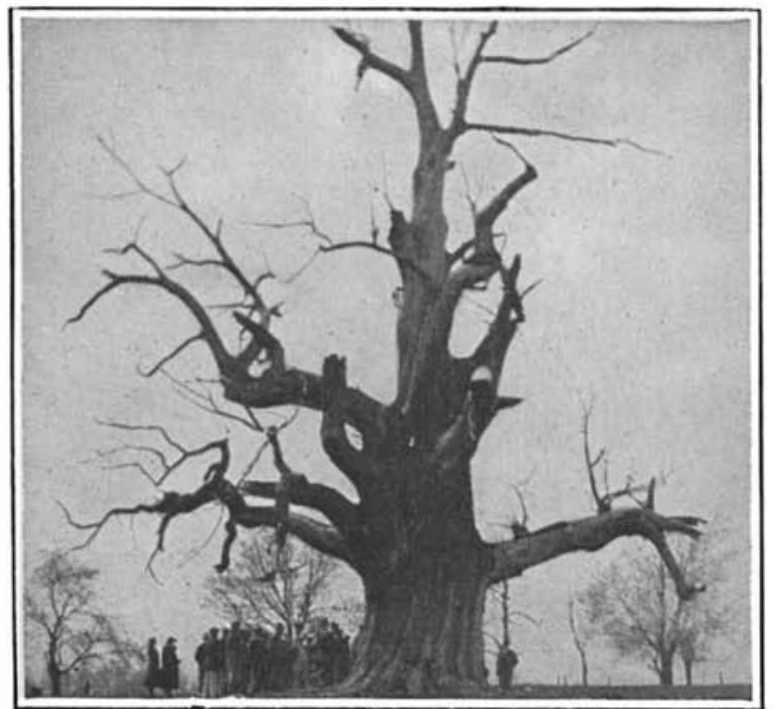

The chestnut tree eleven feet in diameter that was blown up with over 200 pounds of dynamite

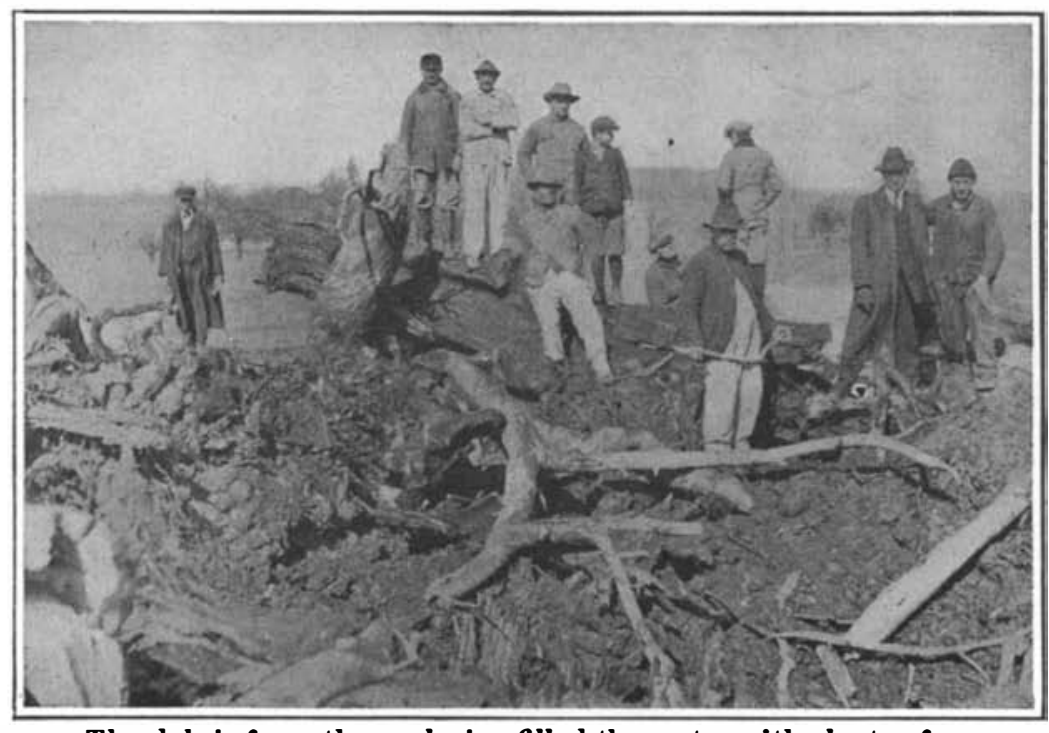

The debris from the explosion filled the crater with plenty of wood left over overdue. The tree was a chestnut measuring 34 feet 6 inches in circumference at the base, and 11 feet in diameter. The height was not so excessive, being but sixty feet. In estimating the age of the tree at 400 years, representatives of the United States Forestry Commission declared it to be by all odds the largest chestnut tree and with little doubt the largest growth in the country outside of .California. (Continued on p. 24l) 
Handling Grain by the Boat-Load Continued from page $2: 6$ )

marine tower and gallerits. rhe incline galler. leading from the marine tower to the plant, is equipped with four belts, each having a capacity of 25,000 bushels per hour. Tnis may be discharged into one hold or split up and fed into four or

Iuch of the grain is received from cars: much of it comes down the river. For the purpose of receiving bargebrought grain, the marine tower is equipped with a pneumatic conveyor, which adapts itself readily to the rise and fall of the Mississippi River-a difference of about 20 feet. The pneumatic conveyor sucks the grain up to the top of the tower, where it is put into hoppers; then it is dropped to one of the four shipping belts running along the inclin gallery into the workhouse. Here it is shot up to the top floor, through the garners into the hopper scales, and finally into the bin

The protection of the grain is guaranteed by a careful system of temperature reading. When 95 degrees is reached, according to the plant foreman, the grain must be cooled. This is done hy lifting it out to the top of the plant, and dropping again, or by using a cooler bin.

The elevator is of steel and reinforced concrete and is entirely operuted by electricity. It is said to be the cleanest in the world, due to its dust collecting sys tem, which not only kceps it clean, but, by removing this danger of fire, gives to the elevator a most adrantageous insurance rate for grain stored.

Hybrid Vigor and Its Meaning (Continued from page 231)

effiect and for the most part incapable of fixation.

For many years it has been thought this stimulation from crossing was of a physiological nature resulting from the union of unlike hereditary complexes. It is a matter of common knowledge that the agr of most species cannot develop into an embryo unless fertilized by the male germ cell usually coming from a different individual. It was argued from this that the union of sex cells from unrelated organisms having diverse heredities would increase this stimulus to development. It is now believed that this is an unnecessary assumption as a more simple interpretation is at hand.

It was due to the Austrian monk, Mendel, that the first real beginning in the study of inheritance was made. While Balzac was writing that "hereditary is a maze in which science loses itself," Mendel in the seclusion of his cloister garden laid the foundation for this far-reaching subject and furnished the key to the problom of consanguinity. Mendel's great contribution was to show that visible characteristics are transmitted from generation to generation independently of each other and unaltered by the accident of having sojourned for a lifetime in a particular individual. But instead of all characteristics being transmitted independently as the work of Mendel first indicated, it has been shown by Bateson in England ancl Morgan in America that characteristics are carried in groups and that it is these groups of hereditary potentialities which Mendelize, that is, which shuffe themselves about and put themselves in different combinations.

These conclusions which have only recently been arrived at were first developed in England by the aid of the common garden flower, the sweet pea. Later the Columbia University laboratory chose an organisin which proved to be admirably well suited for experimental work of this kind. It was the little red-eyed fruit gnat whose tiny presence warns the housewife that some of her fruit is spoiling.

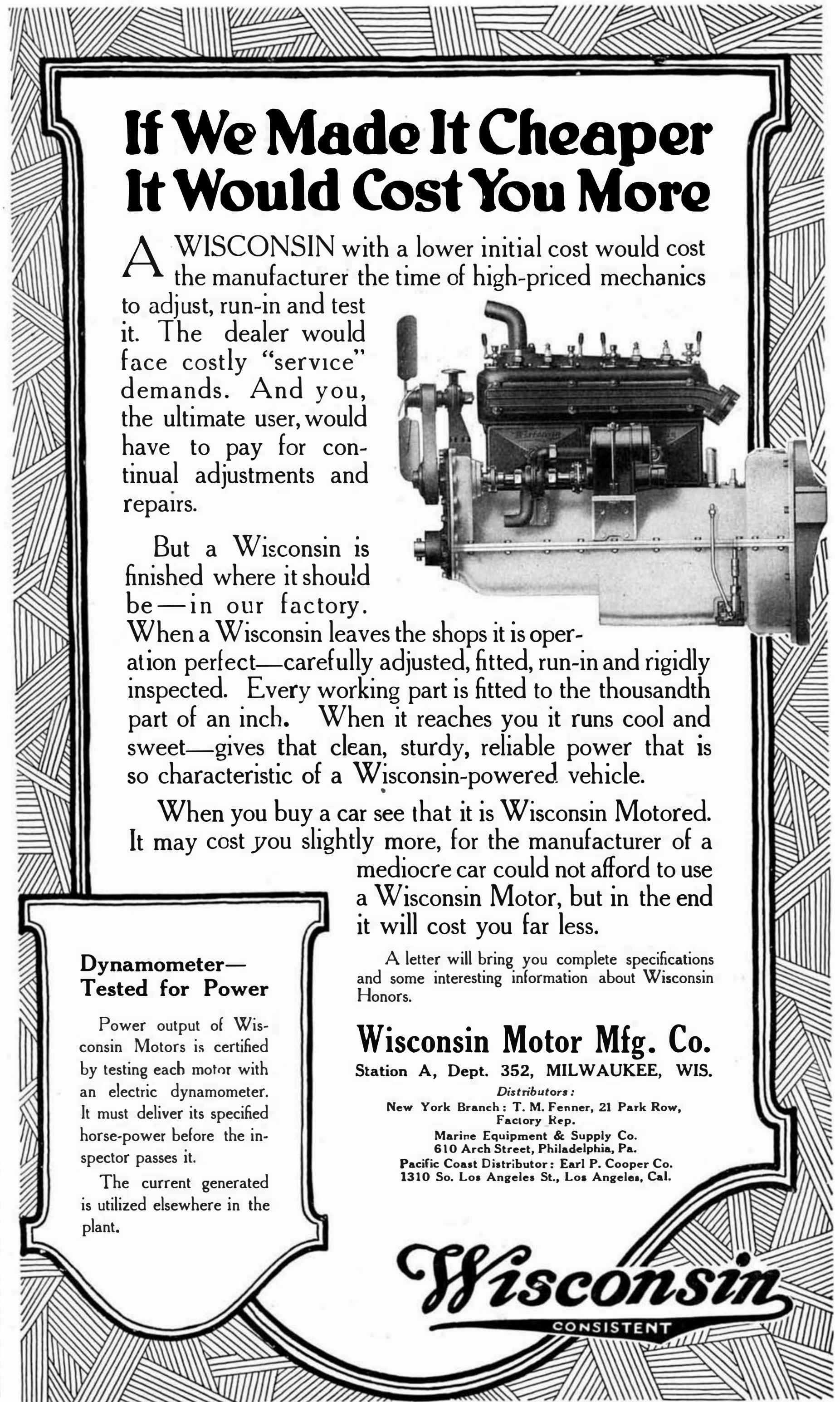



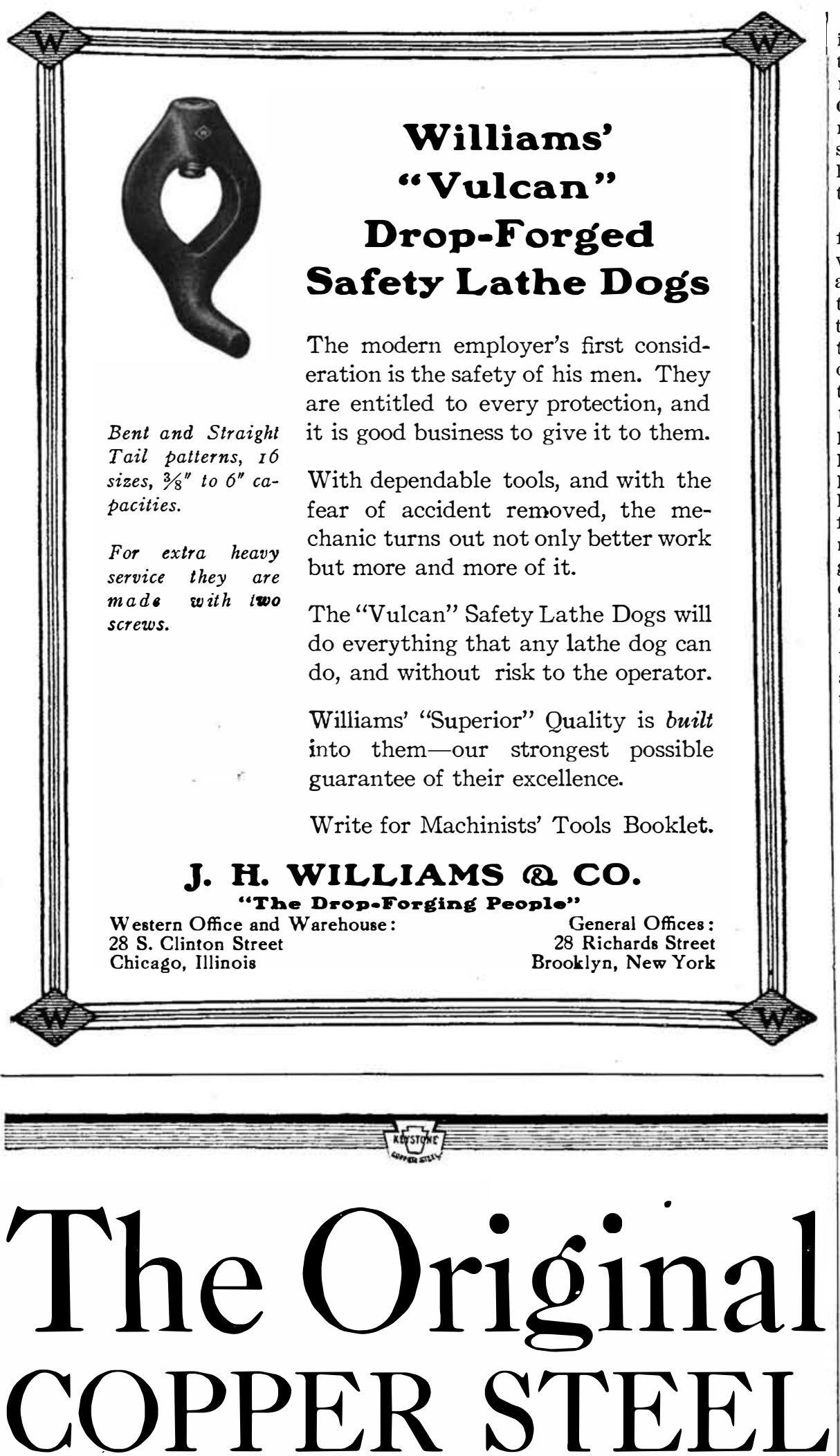

bears this special mark added below regular brands:

WHEN you specify Keystone-you are specifying for satisfaction. The copper steel alloy gives added resistance to rust and unequaled service. Actual time and weather have demonstrated the superiority of this material for all uses where substantial wear and durability are important factors.

Whether you are a large user of sheet and tin mill products, or require only a new metal roof, or the replacement of some exposed sheet metal work, you should know the advantages of Keystone Copper Steel Sheets and Tin Plate. Shall we send Facts booklet?
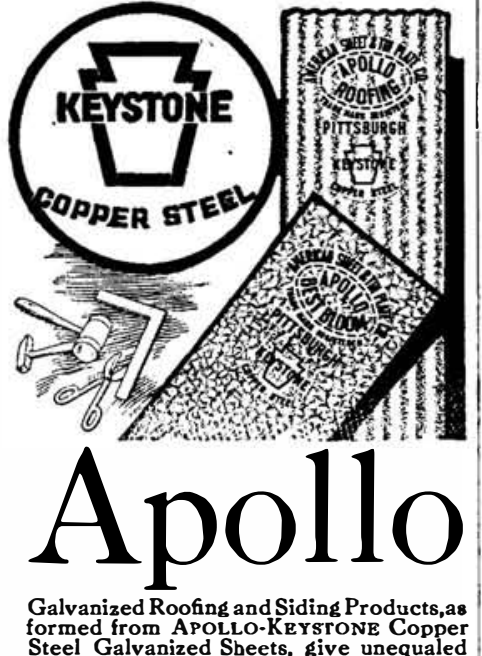
Steel Galvanized Sheets, give unequale
service. Keystone quality is also supplied in Black Sheets, Roofing Tin Plates, etc.
Demand this material for Roofing, Siding
Cornices, Spouting, Gutters. Cisterns, CulCornices, Spouting, Gutters. Cisterns, Cu
verts Tanss, Flumes, metal work. This Company manufactures
Sheet and Tin Mill Products of every
description and for every known purpose. AMERICAN SHEET AND TIN PLATE COMPANY, General Offices: Frick Building, Pittsburgh, Pa
Over one hundred inherited characteristics have been found in this insect. All these hereditary differences are determined by factors carried in four groups. Other animals and plants have different number of groups but the existence of such a method in the transmission of hereditary characters is rapidly being determined for many organisms.

This is the importance which these facts have for the inbreeding problem: when two races are crossed all the characteristics of both parents are transmitted to the hybrid offspring but many of them are unable to express themselves as they are hidcien or covered over by other characteristics. In the majority of cases the more favorable characteristics tend to dominate in this fashion so that the progeny is better able to grow than either parent because it has the best of both parents to draw upon. But when the hybrid itself comes to reproduce, the unfavorable characteristics which lie dormant make their appearance in the progeny so that the extra growth and vigo of the hybrid is only temporary. When segregation comes in the production of the second hybrid generation some of the good qualities go to one individual and some to another. In other words, there is a reduction in size and rapidity of development when close-mating folows crossing, due to the parceling out of the favorable growth factors. Because character factors are carried in groups it is practically impossible to obtain all the good qualities of the hybrid recombined in any one pure-breeding individual. According to this view hybrid vigor results from a temporary securing of all or many of the good qualities from two diverse parents. The reduction in size and vigor is merely going back to the condition of the parents before they were crossed. In this way it is a passing effect leaving no permanent imprint for good or for evil on the race. The consequences of crossing and close-mating are far reaching and indirectly more important than is indicated by these necessarily brief statements.

Hybrid vigor is a cloak of armor protecting many individuals possessing hidden weaknesses and unfavorable characters from the stern but just hand of natural selection. The outcropping of these undesirable traits in human society is sad but nevertheless reliable evidence that they make up a part of the inheritance. feeble-mindedness, insanity, epilepsy, congenital cataract and deaf-mutism may be mentioned as illustrative. In plants chlorophyll deficiency, dwarfness, susceptibility to disease, absence of supporting structures are comparable. Such characteristics and many other weaknesses of a more indefinite nature remain hidden from sight for the most part in wide and continuous crossing. They rarely make their appearance because the chance for the mating of two individuals possessing the same deficiencies is slight Usually what one parent lacks the other supplies so that there is a pooling of spring to make the best of bad ancestry. IVhen like heredities are brought together the undesirables appear although gether the undesirables appear although by the parents transmitting them. Here lies the real danger in consanguinity. In close inter-mating tho chances for like factors to be brought together are enorin sous the results inbreeding, even in small degree if the previous generations hare been long out
crossed, may be decidedly injurious or crossed, may be

But to consider inbreeding as harmful is like blaming the reteetive for the crimes he unearths. Instead of being condemned it should be commended. It is now clearly seen that the system of continued close-mating has greater value in practical plant and animal improvement than previously realized. By subjecting
LEGAL NOTICES

PATE N T S

IF YOU HAVE AN INVENTION 1 which you wish to patent you can
write fully and freely to Munn \& write fully and freely to munn
Co. for advice in regard to the best way of obtaining protection. Please send sketches or a model of your invention and a description of th device, explaining its operation.

All communications are strictly confidential. Our vast practice, extending over a period of seventy years, enables us in many cases to advis in regard to patentability withou any expense to the client. Our HandBook on Patents is sent free on re-

quest. This explains our methods,

terms, etc., in regard to Patents,
Trade Marks, Foreign Patents, etc.

SCIENTIFIC AMERICAN contains Patent Office Notes. Decisions of
interest to inventors- and particulars of reinterest to inventors- and
cently patented inventios

MUNN \& CO., SOLICTTON

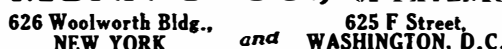
801 Tower Bldg., CHICAGO, ILL.

Annual Subscription Rates

Scientific American Publications Scientific American (established 1845) one year $\$ 5.00$

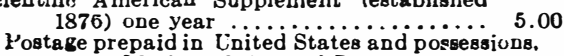
Mexico, Cuba and Pana Foreign Postage

Scientific American $\$ 1.50$ per year additional.
Scientific American Supplement $\$ 1.00$ per yea: ad-

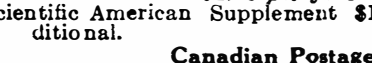

Scientific American 75c per year additional.
Scientific American Supplement 50c per year addithe combined subscription rates and rates to foreign countries, including Canada, will be furnished upon application
Remit by postal or express money order, bank
draft or check

\section{Classified Advertisements} Advertising in this column is $\$ 1.00$ a line. No
less than four nor more than 12 lines accepted.
Count seven words to the line. All orders must be BUSINESS OPPORTUNITIES

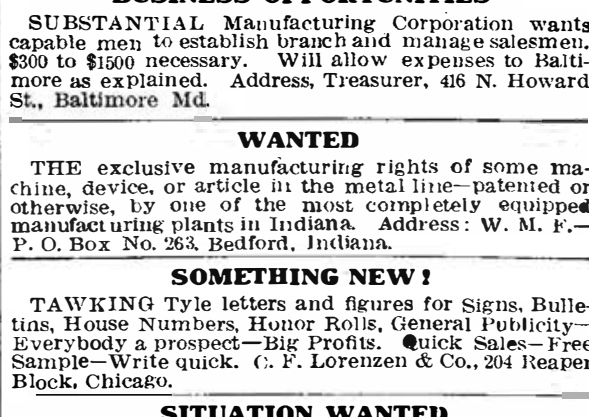

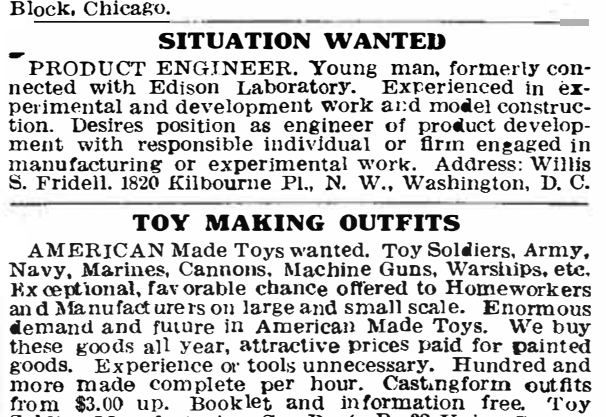
from $\$ 3.00$ up. Booklet and in formation free. Toy
Soldier Manufacturing Co., Dept. B, 32 Union Square.
New York.

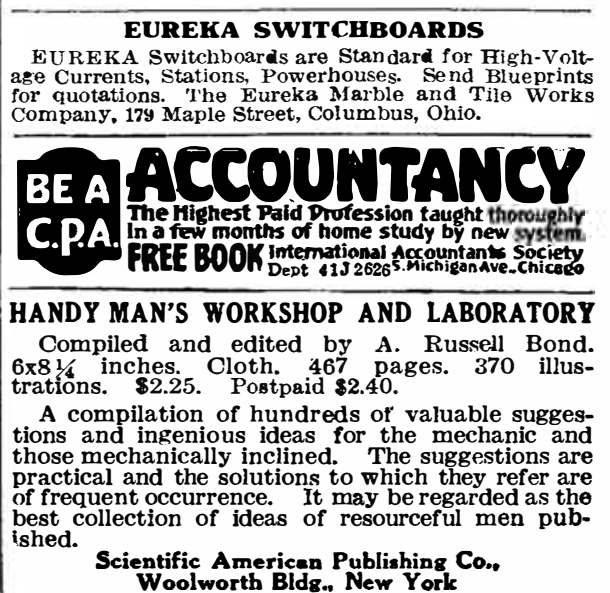



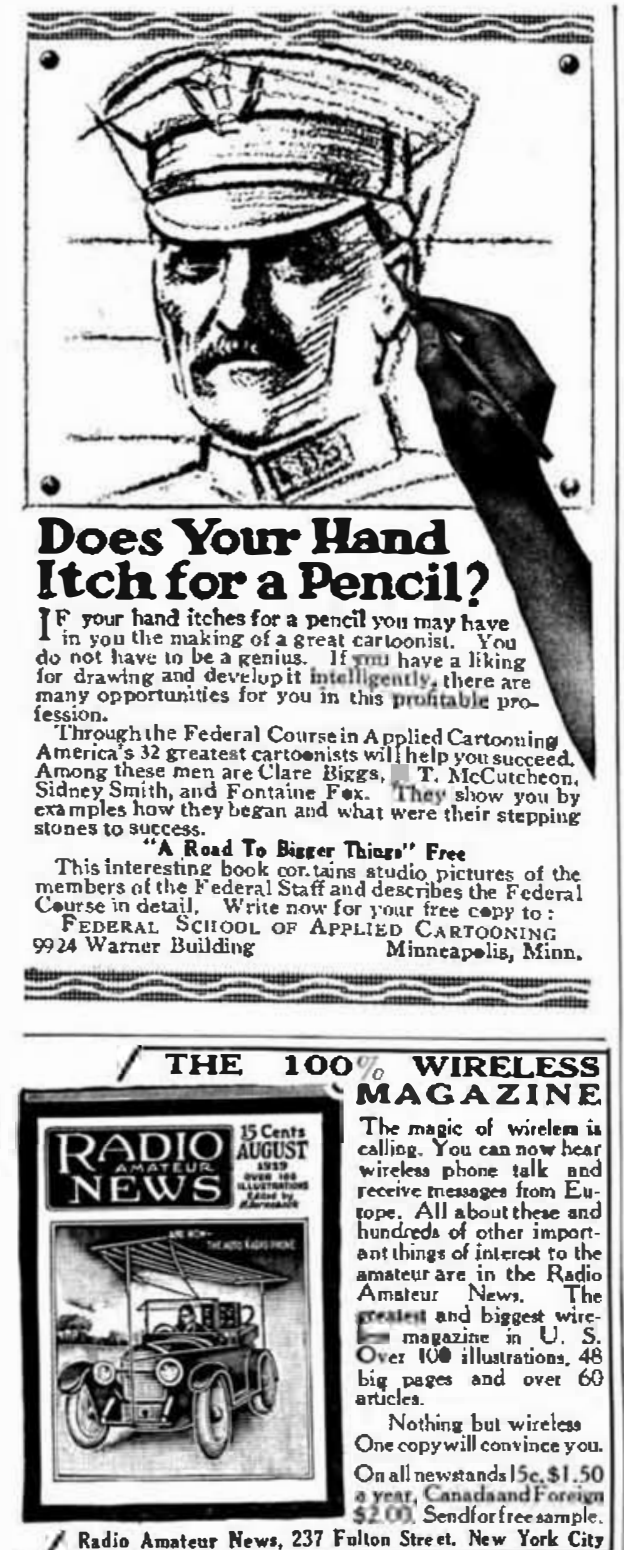

$\angle$ Radio Amateur News, 237 Follon Stre et. New York Cit Sargent's Handbook of AMERICAN PRIYATE SCHOOLS

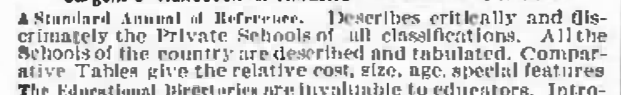

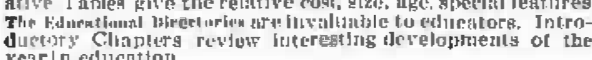

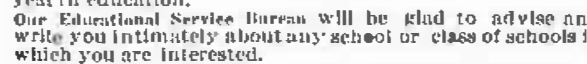
PORTER E. SARGENT, I4 Beacoo Street, Boston, Mass.

LEARN WATCHWORK JEWELRY WORK

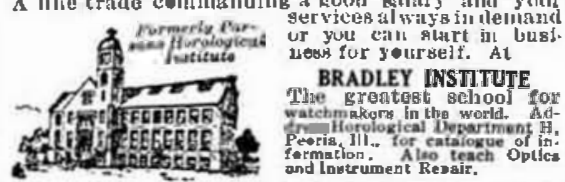
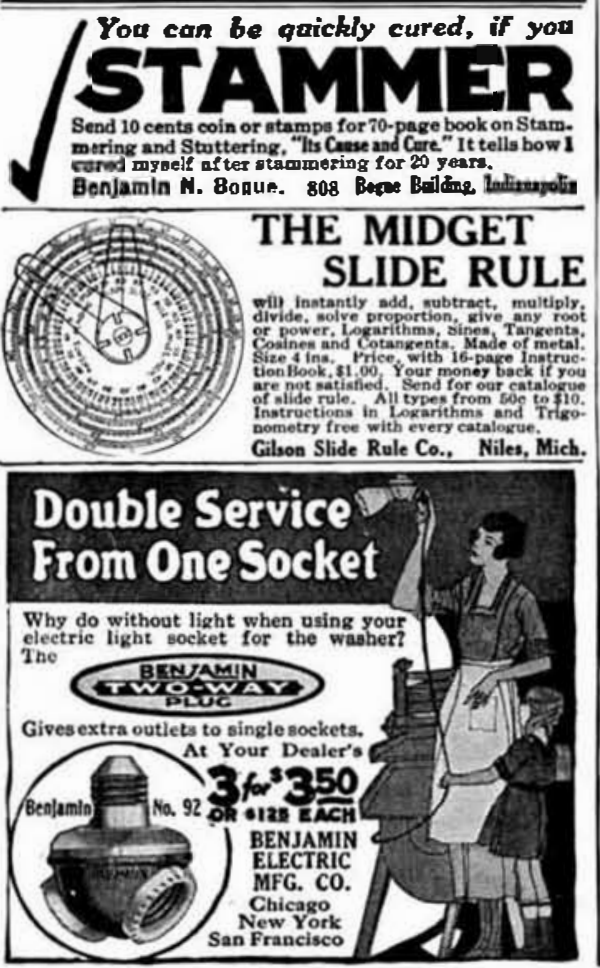

a naturally cross-bred race to a rigju process of continued self-fertilization or inter-inating of the closest kind, [possible werknesses are brought to light and mily be eliminated. The purified types cal trute worth since stripped of the purntection of hybrid vigor they must stand or fall on thejr own merits. In this way inbreeding may be made a potent fuctor for permanent bettermest.

What application these conclusions may ligve in engenlics one ma not even liant a puess. In the present state of our lack of knowledre it is worse than folly to mate recommendations for the guidance of practices in marriage with regard to the conseruences of consanguilmity. In some cases the result of closesnating has been a caln, in others a calamity. It is not yet possible to predict with surety what will be the outcome in particular instances. What is important is the constitution of the ancestry in $r e$ spect to inlserited chiracters. Our pres ent inditference to the keephing of accurate and permiment records of the physjaal and mental trats of every indivtsbal in the country wijl sumetime be lonked ukou as nothing short of criminal catrelessness, The one outstancling ferture is clear that in avoiding relathunship-mar riages to prevent the appoarance of undesilnble chatracters we ale not perrmamentsy halping tle situition in the lpast. Deficienties and wealsnesses insteilel of

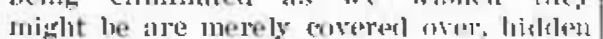
from siglit and hulutiol on as a probiem for fut fure generations to solve.

Uprooting a Tree With Dymamite (Continued from page 231 )

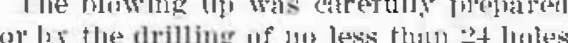
alont the rowas of the griant dereliet. In those were distributerl 110 manduls of ay-

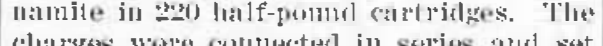

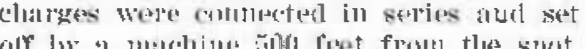

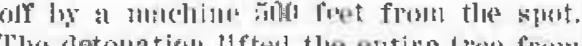
The rletonation llftell the entire Irse from

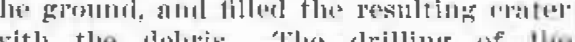

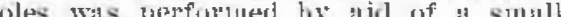

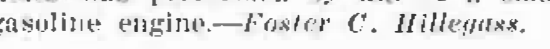

Our Technical Achievements in the Great War (Continuphl from page es3)

growing ascendency of tlie Allies was the entipely to tho Amertans. By November 1 the Allied l'ifle strengll had a superionity nee the German of more thath too, (Kk) rifles.

\section{Thirteen Battles}

American trimpls saw service on mitc tically every stretch of the Western Front. from the Britisl line in Belgium to inactive sectors in the losses. In a sense the entire war on the Western linunt was a single battle, but thirteen majur operations hate heen recognized in which American units were engaged. The names of the battles and the mumber of Amerieans engaged are given in the accompanying table:

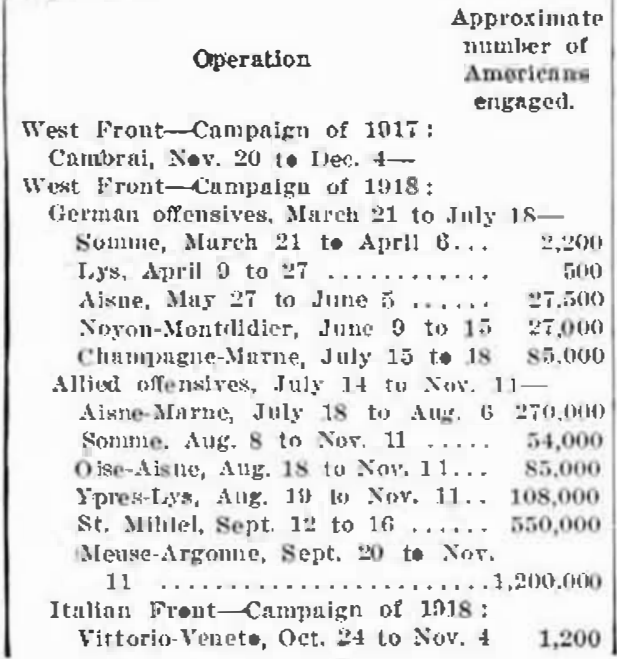

\section{Get the Count in Time}

You want to know machine-output while there's time to improve the rate-of-work on any particular run. Counting production as the machine works shows what you re getting as you go along-makes it easy to hold to a slandard speed when you go by a

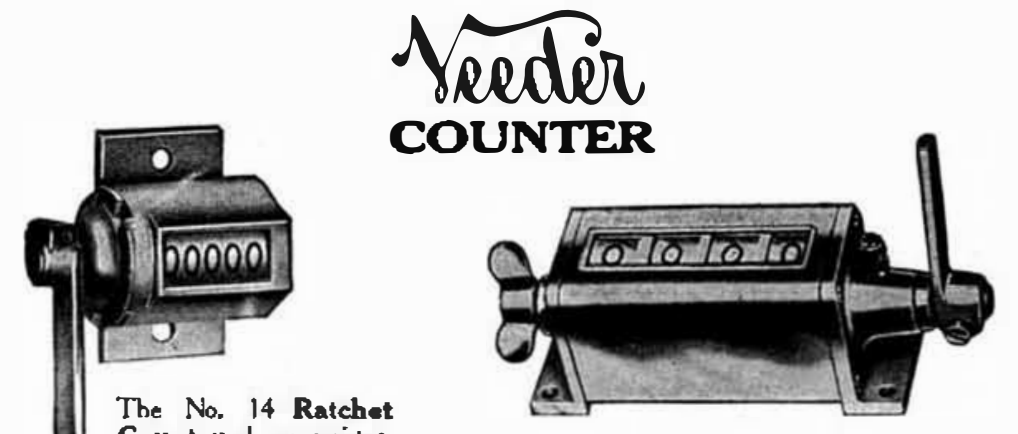

This large Set-Back Rotary Ratchet Counter records the output of punch presses, metal-stamping machines and others where a reciprocating movement indicates an operation. Registers one for each throw of the lever, and sets back to zero from any higure by turning knob once round. Provided with from four to ten figure-wheels, as $\$ 10$. (List.) Equipped with lock and keys to prevent tampering with the record. $\$ 1.50$ extra.

count. The lever is adjustable, allowing the counter to be used a
any angle. (Cut nearly fatl-size)

Whatever purpose you want a counler for, there's a Veeder jusl suilable. Booklet shows styles and sizes for every machine. Send for copy.

\section{The Veeder Mfg. Co., 18 Sargeant St.}

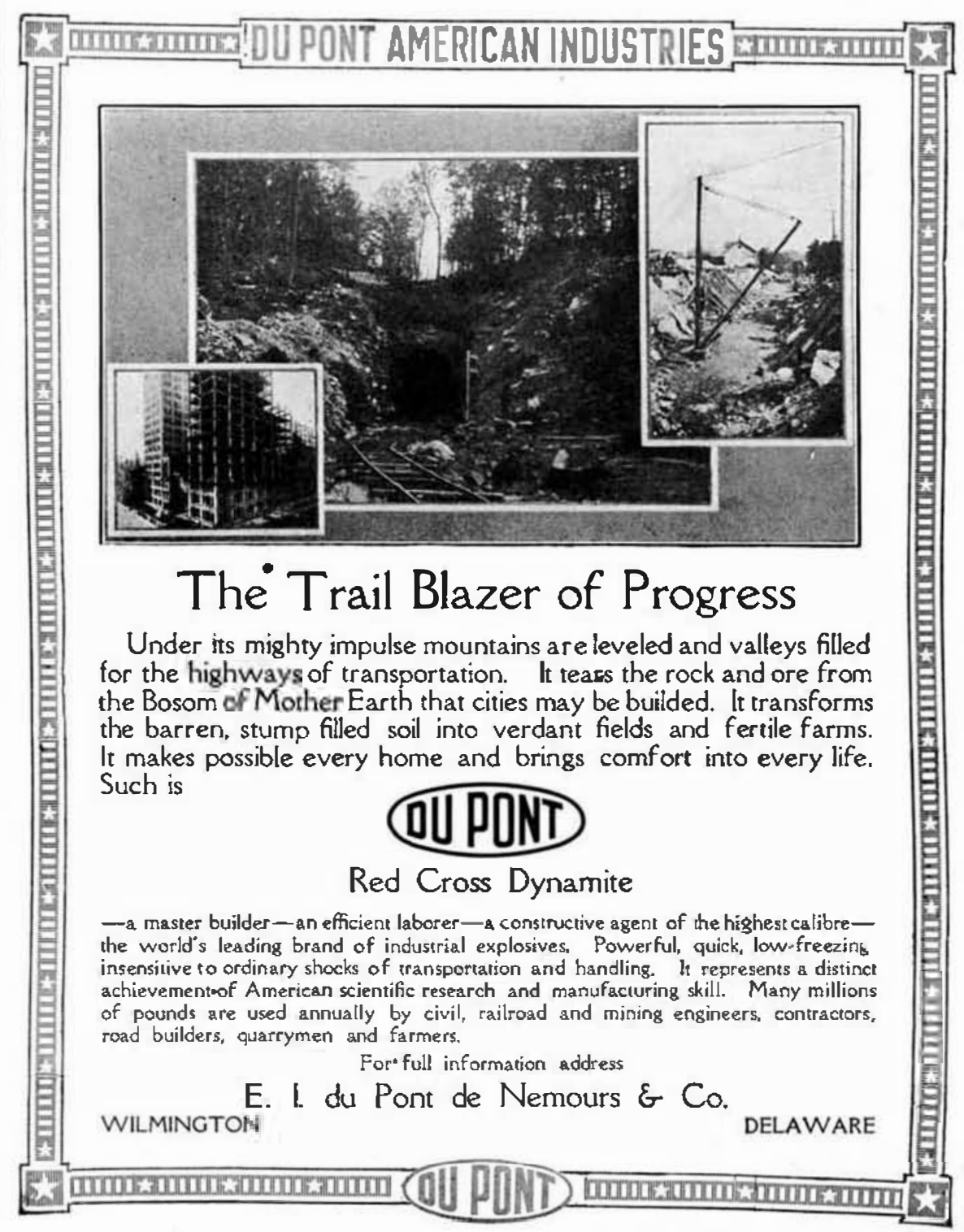

